LOPES, L.B. Listeriose: encefalites nos animais domésticos. PUBVET, Londrina, V. 4, N. 7, Ed. 112, Art. 753, 2010.

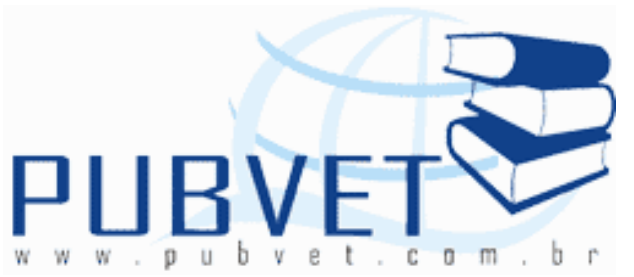

PUBVET, Publicações em Medicina Veterinária e Zootecnia.

\title{
Listeriose: encefalites nos animais domésticos
}

\section{Luciano Bastos Lopes}

Departamento de Medicina Veterinária Preventiva, Escola de Veterinária da UFMG. Médico Veterinário, Doutor em Ciência Animal

\section{Resumo}

A listeriose em animais domésticos pode desencadear uma série de alterações clínicas, sendo os casos de encefalites os mais comuns entre as espécies. Além de ser uma zoonose, a listeriose causa perdas diretas pela morte de animais ou pela necessidade de seu sacrifício, gastos com medicamentos, diminuição da produção e casos esporádicos de abortos. A Listeria monocytogenes tem sido isolada de diferentes produtos de origem animal tais como leite cru, carne bovina, suína, de aves, peixes, embutidos além de produtos de origem vegetal. Palavras chave: listeriose, zoonose, encefalites

\section{Listeriosis: encephalitis in domestic animals}

\section{Abstract}

Listeriosis in domestic animals can induce a series of clinical disorders, being cases of encephalitis the most common among the species. Besides being a zoonosis, listeriosis it causes direct losses in consequence of death of animals or their sacrifice, expenses with medicines, decrease of the production and sporadic cases of abortions. The Listeria monocytogenes has been isolated of 
LOPES, L.B. Listeriose: encefalites nos animais domésticos. PUBVET, Londrina, V. 4, N. 7, Ed. 112, Art. 753, 2010.

different such products of animal origin as raw milk, bovine meat, swine, poultry, fish, processed meat and vegetables.

Words key: listeriosis, zoonosis, encephalitis

\section{INTRODUÇÃo}

O agente da listeriose foi descrito pela primeira vez por Murray e colaboradores em 1926. De acordo com a história, alguns animais de laboratório desenvolveram a doença nos laboratórios da Universidade de Cambridge. O microorganismo foi então isolado e a doença foi reproduzida de forma experimental em coelhos e outras cobaias onde foi possível identificar uma monocitose persistente nestes animais. O microorganismo foi então denominado Bacterium monocytogenes. Com o passar dos anos outros nomes foram sugeridos para o agente, dentre eles Listerella hepatolytica, Listerella monocytogenes, Erysipelothrix monocytogenes em razão da similaridade com este gênero de bactéria e, finalmente em 1940, Listeria monocytogenes. Atualmente outras cinco espécies são reconhecidas como a Listeria ivanovii, $L$. innocua, L. welshimeri, L. grayi e por último a L. seeligeri. Apenas a Listeria monocytogenes e a Listeria ivanovii são potencialmente patogênicas.

Após o isolamento inicial descrito em 1926 a bactéria tem sido isolada em uma grande variedade de animais selvagens, animais domésticos, aves, peixes e no homem. Em seres humanos, a infecção por Listeria monocytogenes normalmente causa septicemia ou meningite, entretanto, a doença pode se manifestar de diversas formas dependendo do órgão infectado. Pode haver casos de pneumonia, endocardite, lesão cutânea e conjuntivite. Os recémnascidos e mulheres grávidas são particularmente mais suscetíveis a bactéria. As pessoas imunodeprimidas e pacientes com AIDS estão expostas a um risco maior.

A Listeria monocytogenes tem sido isolada de diferentes produtos de origem animal tais como leite cru, carne bovina, suína, de aves, peixes, embutidos além de produtos de origem vegetal e refeições preparadas. Além de ser uma zoonose, a listeriose causa perdas diretas pela morte de animais ou pela 
LOPES, L.B. Listeriose: encefalites nos animais domésticos. PUBVET, Londrina, V. 4, N. 7, Ed. 112, Art. 753, 2010.

necessidade de seu sacrifício, gastos com medicamentos, diminuição da produção e casos esporádicos de abortos. Alguns aspectos epidemiológicos e da patogênese da infecção nos ruminantes pela Listeria monocytogenes ainda não estão bem esclarecidos sendo necessária à realização de mais estudos envolvendo este agente. A listeriose ocorre normalmente nos meses de inverno onde os animais são confinados pela necessidade da suplementação de matéria seca nesta época, sendo particularmente comum a sua ocorrência em rebanhos tratados a base de silagem.

\section{Etiologia}

Parasita intracelular facultativo, Gram +, catalase positiva, não esporulada, de 1 a $2 \mu \mathrm{m}$ de comprimento e 0,5 $\mu \mathrm{m}$ de largura, vive freqüentemente associada a outras bactérias saprófitas presentes na matéria orgânica em decomposição. A Listeria monocytogenes é extremamente resistente às condições ambientais adversas e podem sobreviver por anos no solo, material fecal, água e alimento contaminado. Com base nos antígeno somático $(\mathrm{O})$ e flagelar $(\mathrm{H})$, vários sorotipos de Listeria monocytogenes podem ser identificados, dentre eles: 1/2 $a, 1 / 2$ b , 1/2 c, 3 a, 3 b, 3 c e 4 b, no entanto os sorotipos $1 / 2$ a e 4 b são os maiores causadores de encefalite nos ruminantes.

Em meio de cultura, as colônias são pequenas, lisas, apresentando uma coloração branca, aspecto leitoso além de produzir $\beta$-hemólise em ágar sangue. Seu crescimento ocorre na faixa de temperatura de $3^{\circ}$ a $44^{\circ} \mathrm{C}$ onde temperatura ótima é de $30^{\circ}$ a $37^{\circ} \mathrm{C}$. Nestas condições, em um ou dois dias as colônias já podem ser visualizadas. A multiplicação ocorre em microaerofilia, $10 \%$ de $\mathrm{O}_{2}$. A Listeria sp. cresce melhor na escala de $\mathrm{pH}$ entre 6,0 e 8,0 sendo que algumas espécies crescem dentro de uma escala de $\mathrm{pH}$ entre 4,1 a 9,6. Contudo $\circ \mathrm{pH}$ mínimo de crescimento da bactéria está em função da temperatura de incubação, dos nutrientes, da atividade de água, da presença e quantidade de $\mathrm{NaCl}$ e de outros sais ou inibidores.

\section{Epidemiologia}

A encefalite é a forma mais comum de listeriose em ruminantes, entretanto, outras síndromes podem ocorrer em razão da infecção pela Listeria 
LOPES, L.B. Listeriose: encefalites nos animais domésticos. PUBVET, Londrina, V. 4, N. 7, Ed. 112, Art. 753, 2010.

monocytogenes, incluindo aborto, septicemia, mastite e conjuntivite. Os casos de encefalite são descritos mais comumente em ovinos e bovinos e em menor número nos caprinos. Não há diferença de susceptibilidade entre sexo, raça ou idade, entretanto a doença ocorre freqüentemente quando há troca dos dentes e erupção dentária nos animais jovens.

Os casos de encefalite normalmente envolvem mais de um animal do rebanho em um curto espaço de tempo, podendo ocorrer em qualquer época do ano apesar de serem mais comuns os casos na época do inverno onde os animais são confinados e recebem alimentos estocados. Fatores climáticos e de manejo podem predispor os casos de encefalite em virtude de um aumento do estresse do rebanho e da contaminação ambiental. O consumo de silagem é, independente da planta forrageira utilizada, o fator de risco mais importante para o surgimento destes casos de encefalite. Entretanto, a qualidade da silagem é determinante para a presença da Listeria monocytogenes em razão de um $\mathrm{pH}$ superior a 5,5. Abaixo deste valor, o crescimento da bactéria é inibido evitando-se assim a contaminação do material ensilado. Nem todos os casos de encefalite estão associados ao consumo de silagem contaminada, historicamente outros casos foram encontrados em rebanhos consumindo pastagem, feno, cama de frango e concentrado a base de grãos.

\section{4. patogenia}

A contaminação ocorre pela ingestão de alimento contaminado tanto para o homem quanto para os animais domésticos. Após a penetração e multiplicação nos enterócitos, a bactéria é fagocitada pelos macrófagos e envolvida por um vacúolo no citoplasma da célula. A expressão de Listeriolisina O (LLO) pela bactéria possibilita o rompimento do vacúolo sendo este um dos fatores mais importantes de virulência da bactéria. No citoplasma, a Listeria monocytogenes é capaz então de se multiplicar e infectar outras células adjacentes através da ação de uma proteína sintetizada pelo gene actA que promove a polimerização dos filamentos de actina da célula do hospedeiro, formando-se assim longas caudas em uma das extremidades da célula bacteriana possibilitando o seu deslocamento no citoplasma. Dessa forma a bactéria se movimenta de célula 
LOPES, L.B. Listeriose: encefalites nos animais domésticos. PUBVET, Londrina, V. 4, N. 7, Ed. 112, Art. 753, 2010.

para célula sem, no entanto entrar em contato com o meio extracelular. A ação de proteínas denominadas internalinas possibilita a penetração da bactéria no interior das células do hospedeiro.

ENCEFALITE: A primeira descrição de um caso de encefalite envolvendo a infecção pela Listeria sp. ocorreu em ovinos da Nova Zelândia e foi descrita por Gill em 1931. A doença foi identificada como circling disease em virtude da sua sintomatologia clínica conseqüente das lesões cerebrais. Por muitos anos a patologia da encefalite tem sido o objeto de muitos estudos e de especulação. Apesar da ingestão de material contaminado ser o fator predominante para a ocorrência da doença, há poucas evidências na literatura que a transmissão via hematógena está envolvida na patogênese da doença, entretanto esta possibilidade não deve ser descartada havendo a necessidade de mais estudos sobre a patogenia do agente. Experimentalmente a encefalite não pôde ser reproduzida pela injeção intracarótida, intracerebral, intramuscular, intrarumenal ou instilação conjuntival segundo alguns autores. O mecanismo mais aceito atualmente é a ascensão da bactéria via nervo trigeminal, onde ocorreria uma migração intra-axonal até o gânglio trigeminal atingindo então o sistema nervoso central.

ABORTO: O últero prenhe é altamente susceptível a infecção via hematógena sendo o período de incubação de 5 a 12 dias. Podem ser encontradas lesões amareladas na placenta além de necrose de cotilédones, placentite e exudato de coloração vermelho amarronzado. O feto se encontra freqüentemente autolisado e ocasionalmente podem ser encontradas lesões macroscópicas no fígado e baço.

SEPTICEMIA: É relativamente incomum e geralmente ocorre em animais neonatos em razão da infecção intra-uterina. As lesões mais comuns são necroses hepáticas com lesões nodulares espalhadas pelo órgão. As lesões podem ser encontradas também no baço mas raramente estão presentes em 
LOPES, L.B. Listeriose: encefalites nos animais domésticos. PUBVET, Londrina, V. 4, N. 7, Ed. 112, Art. 753, 2010.

outros tecidos. Em ovelhas prenhes podem ocorrer surtos de septicemia onde os animais apresentam um quadro febril e de diarréia profusa.

\section{Sinais Clínicos}

RUMINANTES: Inicialmente os animais apresentam sintomas gerais como prostração e anorexia e, em dois ou três dias, começam a demonstrar sintomatologia nervosa. Em ovelhas e vacas no período seco, as alterações iniciais podem passar despercebidas sendo que os sintomas nervosos podem aparecer sem qualquer sinal de alerta. A doença se apresenta de forma aguda e de rápida progressão. Lesões macroscópicas normalmente não são encontradas, mas podem ser identificadas pela histopatologia sendo os sinais patognomônicos. São encontrados focos de células inflamatórias ao redor dos vasos sanguíneos com predominância de linfócitos e ocasionalmente neutrófilos.

Os sinais nervosos normalmente refletem as lesões no nervo trigeminal, facial, vestibulococlear e glossofaríngeo, embora possam acometer outros nervos craniais além do sistema nervoso central e medula espinhal. Freqüentemente uma meningite acompanha estes casos de encefalite. Os primeiros sinais podem aparecer como contrações musculares superficiais ou paralisia regional dos membros, torcicolo, febre além de incordenação motora e ataxia. Os animais se locomovem sem uma orientação definida e apresentam uma tendência de deslocamento em círculos sempre na mesma direção. Em alguns casos pressionam a cabeça contra objetos e sinais de mania ou obsessão. A paralisia dos músculos faciais acarreta em uma dificuldade de mastigação, salivação excessiva, desidratação, acúmulo de alimento na cavidade oral, refluxo de alimento e aspiração do conteúdo rumenal, queda da orelha e do lábio inferior. A perda da função motora ao redor dos olhos acarreta em uma queratite secundária em virtude da falta de reflexo palpebral.

Outros sintomas podem aparecer como, estrabismo, cegueira, nistagmo, opstótomo, protusão da língua além da sua falta de tônus, tremores da cabeça, movimentos de pedalagem, mamite além de abortos no terço final de 
LOPES, L.B. Listeriose: encefalites nos animais domésticos. PUBVET, Londrina, V. 4, N. 7, Ed. 112, Art. 753, 2010.

gestação. Em pequenos ruminantes os quadros de encefalite são mais agudos que nos bovinos e, em dois ou três dias, estes animais costumam morrer. Se não houver tratamento, a fatalidade dos casos chega a $100 \%$. O período de incubação varia bastante, mas dados experimentais e de campo, sugerem estar em torno de duas a seis semanas.

Suínos: Normalmente estes animais apresentam sinais sistêmicos discretos além dos sinais de encefalite, contudo edema de pálpebra é um sinal freqüentemente encontrado nesta espécie. Usualmente a paralisia ocorre em um ou mais membros progredindo até a fatalidade em duas ou três semanas. Ocasionalmente ocorrem casos de septicemia onde os animais acometidos morrem em poucos dias. Na necropsia são encontradas lesões necróticas distribuídas por vários órgãos. Para esta espécie os casos de listeriose normalmente são fatais.

AVES: Os quadros de listeriose em aves quando ocorrem normalmente são do tipo septicêmico. Macroscopicamente são encontradas lesões necróticas no fígado e miocárdio, O sistema nervoso central é afetado ocasionalmente resultando em paralisia e torcicolo.

\section{Diagnóstico}

O diagnóstico é na maioria das rezes realizado com base na sintomatologia clínica e necropsia. Os parâmetros hematológicos normalmente estão dentro dos limites normais nos casos de encefalite. Monocitose não ocorre rotineiramente em ruminantes como nas espécies monogástricas. Como diagnóstico diferencial, deve-se levar em conta os casos de otite, abscessos ou tumores cerebrais, traumas, obstrução esofageana, megaesôfago, hipocalcemia, botulismo, raiva, artrite encefalite caprina e encefalopatia espongiforme bovina nos países onde a doença ocorre.

A necropsia é a forma mais eficiente de diagnóstico, no entanto os cuidados devidos devem ser tomados durante a sua realização. Na maioria dos casos, não são observadas lesões macroscópicas do cérebro embora possa haver 
LOPES, L.B. Listeriose: encefalites nos animais domésticos. PUBVET, Londrina, V. 4, N. 7, Ed. 112, Art. 753, 2010.

meningite evidente. As alterações microscópicas podem ser observadas através da histologia onde são encontradas áreas de necrose com intenso infiltrado de macrófagos e neutrófilos formando microabcessos. As lesões encontradas na histopatologia normalmente são mais agudas em pequenos ruminantes com características neutrofílicas, já nos bovinos, são mais comuns à formação de microgranulomas nestes casos de encefalite.

Pode-se ainda tentar o isolamento do agente e a coloração de Gram a partir do material coletado durante a realização da necropsia. Da mesma forma, é possível a realização de imunohistoquímica a partir deste material sendo esta técnica mais sensível quando comparada à cultura e isolamento bacteriano. Embora os métodos baseados na deteç̧ão de anticorpos possam ser utilizados, normalmente estas técnicas não apresentam boa especificidade sendo comuns à ocorrência de reações cruzadas com Staphylococcus aureus e Enterococcus sp.. A técnica de PCR tem sido desenvolvida para detecção deste agente embora não venha sendo empregada como rotina nos laboratórios.

\section{Tratamento \& Controle}

Os tratamentos dos casos de encefalite são efetivos apenas quando diagnosticados precocemente. Em muitas das vezes, os animais já apresentam um quadro avançado da doença onde os danos cerebrais já são muito extensos. Nestes casos o tratamento deve ser visto com ressalvas, pois as chances de sucesso são muito pequenas. Nos casos onde os ovinos e caprinos são acometidos a fatalidade pode ser alta, mesmo quando o tratamento é realizado de forma precoce.

Antibioticoterapia parenteral é a principal forma de tratamento nos casos de listeriose encontrados no rebanho, podendo ainda ser administrados antiinflamatórios, fluidoterapia, transfusão de suco de rúmen e o fornecimento de vitaminas do complexo B. Penicilina (22.000 a 44.000 UI/kg/IM $4 \times$ ao dia) ou oxitetraciclina ( $20 \mathrm{mg} / \mathrm{kg} / \mathrm{IV} \quad 1 \times$ ao dia) são os antibióticos mais freqüentemente utilizados nos casos de encefalite embora tenham sido 
LOPES, L.B. Listeriose: encefalites nos animais domésticos. PUBVET, Londrina, V. 4, N. 7, Ed. 112, Art. 753, 2010.

relatados alguns casos de insucesso com ambas as drogas. A terapia deve se estender por 2 a 4 semanas para completa resolução e diminuição dos casos de recidiva.

A prevenção é feita através da redução da exposição ao agente no meio ambiente, nos alimentos e dos fatores estressantes. Um cuidado especial deve ser tomado com o armazenamento da silagem nos rebanhos confinados. Nos casos onde haja mofo ou alteração de odor, o material contaminado deve ser descartado em vez de ser fornecido aos animais. Com relação aos ovinos, deve ser tomado um cuidado em especial selecionado a melhor silagem para estes animais por serem mais susceptíveis que os bovinos. Após o seu fornecimento, os restos devem ser removidos quando presentes no chocho de alimentação.

Um grande número de vacinas vem sendo desenvolvidas ao longo dos anos. Seja através da utilização de bacterinas ou de vacinas atenuadas, algumas vem apresentando um bom resultado com uma diminuição da incidência ou severidade dos casos clínicos. Entretanto, estas vacinas não estão disponíveis comercialmente no mercado talvez pela natureza esporádica dos casos de listeriose e falta de interesse por parte da indústria de insumos veterinários.

\section{REFERÊNCIAS BIbLIOGRÁfICAS}

BLENDEN, D. C.; KAMPELMACHER, E. H.; TORRES-ANJEL, M. J. Listeriosis. JAVMA, v. 191, p. 1546 - 1551, 1987.

DHAWEDKAR, R. G. Studies on mechanism of bacterial abortions with particular reference to Listeria monocytogenes and Salmonela abortus ovis. Tese de doutorado, Higher Veterinary Medical Institute, 1968.

FARRAG, S. A.; MARTH, E. H. Interactions between Listeria monocytogenes and other psychrotrophic bacteria in dairy foods: a review. Food Australia, v. 44, p. 281 - 284, 1992.

GILL, D. A. Circling disease of sheep in New Zealand. Veterinary Journal, v. 87, p. $60-74$, 1931.

GIRDHAR, O. P.; GARG, S. R. Prevalence of Listeria in animal farms. Indian J. of Anim. Sci., v. 42, p. $847-849,2002$.

HYSLOP, N, ST, G.; OSBORNE, A. D. Listeriosis: a potential danger to public health. The Veterinary Record, v. 71, p. 1082 - 1090, 1959. 
LOPES, L.B. Listeriose: encefalites nos animais domésticos. PUBVET, Londrina, V. 4, N. 7, Ed. 112, Art. 753, 2010.

KATHARIOU, S. Listeria monocytogenes virulence and pathogenicity, a food safety perspective. J. of Food Protection, v. 165, p. 1811 - 1829, 2002.

LOW, J. C.; DONACHIE, W. A review of Listeria monocytogenes and Listeriosis. The Veterinary Journal, v. 153, p. 9 - 29, 1997.

MARTH, E. H. Disease characteristics of Listeria monocytogenes. Food Technology. p. 165 $168,1988$.

MCLAUCHLIN, J. Animal and human Listeriosis: a shared problem? The Veterinary Journal, v. 153, p. 3 - 5, 1997.

MORIN, D. E. Brainstem and cranial nerve abnormalities: Listeriosis, otitis media/ interna and pituitary abscess syndrome. Vet. Clin. Food Anim., v. 20, p. 243 - 273, 2004.

SCHLECH, W. F. Virulence characteristics of Listeria monocytogenes. Food Technology, p. 176 - 178, 1988.

SEELINGER, H. P. R. Listeriosis. New York, Hafner Publishing Company, 1961, 308 p.

VÁZQUEZ-BOLAND, J. A.; Kuhn, M.; BERCHE, P.; CHAKRABORTY, T.; DOMÍNGUEZ-BERNAL, G.; GOEBEL, W., GONZÁLEZ-ZORN, B.; WEHLAND, J.; KREFT, J. Listeria Pathogenesis and Molecular Virulence Determinants. Clinical Microbiology Reviews, V. 14, p. 584 - 640, 2001.

WOO-SAM, N. H. Listeriosis in a Holstein cow. Can. Vet. J., v. 40, p. 506 - 508, 1999. 